\title{
Gamificação na 8르 Pré-Jornadinha Nacional de Literatura
}

Fabiane Verardi"

Renata Andreolla**

\section{Resumo}

O presente trabalho tem como objetivo analisar a contribuição da gamificação na construção e formação de novos leitores por meio do aplicativo JornadApp na Escola, que foi usado como recurso na $8^{\text {a }}$ pré-Jornadinha Nacional de Literatura. Os referenciais teóricos dessa pesquisa se baseiam nos estudos de Michele Petit, na questão de formação do leitor; nos estudos de James Paul Gee, Jane McGonigal no que se refere aos games e gamificação; e sobre aprendizagem lúdica e gamificação na educação, as contribuições de Lucia Santaella. A pesquisa, de caráter descritivo-qualitativa, observou, registrou e analisou os dados à luz dos pressupostos teóricos elencados, sem a interferência do pesquisador e buscou apresentar a relevância do letramento literário por meio de práticas gamificadas, concluindo que a gamificação apresenta-se como uma estratégia viável para o engajamento e motivação dos alunos no desenvolvimento de competências na aprendizagem de literatura, devendo ser disseminada entre a comunidade docente a fim de se obter melhores resultados no que tange à formação de leitores.

Palavras-chave: Literatura. Gamificação. Jornadinha Nacional de Literatura. JornadApp na Escola.

\section{Introduçãa}

A leitura tem grande importância na vida das pessoas. É por meio dela que nos tornamos cidadãos mais críticos, buscamos entender o mundo em que vivemos, podemos viajar para lugares inimagináveis e distantes sem sair do lugar. A leitura, sobretudo a literária, que deve ser iniciada desde a mais tenra fase da vida das pessoas, estimulada,

\footnotetext{
* Possui graduação em Letras pela Universidade de Passo Fundo (1991), Mestrado em Letras (Teoria Literária) pela Pontifícia Universidade Católica do Rio Grande do Sul (1999), Doutorado em Letras (Teoria Literária) pela Pontifícia Universidade Católica do Rio Grande do Sul (2004) e Pós-Doutorado pela Universidade de Coimbra (2019). Atualmente é professora Titular II da Universidade de Passo Fundo, no curso de Letras, no Programa de Pós-Graduação em Letras e Coordenadora das Jornadas Literárias de Passo Fundo. Vice-Coordenadora do Grupo de Trabalho Leitura e Literatura Infantil e Juvenil da Associação Nacional de Pós-Graduação e Pesquisa em Letras e Linguística (ANPOLL) (www. gtllij.com.br), biênio 2018-2020. Desenvolve projetos na linha de pesquisa de Leitura e Formação de Leitor, focalizando seus trabalhos na questão da leitura na escola, metodologias de ensino da literatura infantil e juvenil. É líder do Grupo de Pesquisa CNPq: Sobre Ensino de Literatura. E-mail: fabianevb@uol.com.br

** Doutoranda do Programa de Pós-Graduação em Letras da Universidade de Passo Fundo. Bolsista Capes/ Prosuc. E-mail: reandreolla@gmail.com
}

Data de submissão: abr. 2019 - Data de aceite: jul. 2019 http://dx.doi.org/10.5335/rdes.v15i2.9725 
primeiramente, pela família, e, depois, pela escola, a qual, muitas vezes, a utiliza apenas para trabalhos gramaticais e decodificação, desvirtuando o papel literário, suprimindo seu encantamento e não cumprindo a tarefa principal: formar leitores.

Sabe-se que a leitura é onipresente no dia a dia das pessoas: seja em casa, na escola ou no trabalho. A formação do leitor deveria iniciar na família, a primeira instância mediadora de leitura, mas, muitas vezes, inicia-se no âmbito escolar e se processa em longo prazo, tendo como mediador o professor. E trabalhar com leitura em sala de aula tem sido debatido no âmbito educacional. Questiona-se como é possível aprender a ler na escola?; qual a importância dessa leitura na formação cidadã e crítica do aluno?; o que se lê em sala de aula contribui para a formação reflexiva e crítica dos estudantes?

Essas preocupações (não de hoje) objetivaram um dos maiores eventos literários do país: a Jornada Nacional de Literatura. É por isso que, desde 1981, a Universidade de Passo Fundo, localizada na cidade de Passo Fundo, Rio Grande do Sul, tem por objetivo a formação de leitores por meio do trabalho conjunto com escolas da região, tanto públicas como particulares, estimulando o envolvimento de alunos, professores, pais e comunidade geral com a leitura, empregando metodologia diferenciada: a leitura antecipada das obras dos autores participantes da movimentação literária.

Com o passar das edições, a estrutura foi se renovando, incorporando a ela uma série de atividades culturais. A programação, antes voltada para debates sobre literatura, educação e cultura, ganhou uma série de outras atrações, entre as quais exposições, espetáculos teatrais, apresentações musicais e concursos, sempre com a proposta de aproximar os autores do público e de formar leitores.

A partir de 2001 , foi realizada a $1^{\text {a }}$ Jornadinha Nacional de Literatura, voltada às crianças e jovens, que possibilitou - a esse público - a interação com os escritores, ilustradores e artistas, proporcionando o compartilhamento de conhecimentos e experiências literárias e investindo na formação de novos leitores.

Cabe destacar que o diferencial das Jornadas Literárias é marcado pelas atividades de Pré-Jornada e Pré-Jornadinha, que antecedem à grande festa da literatura. Trata-se de uma movimentação cultural que tem por finalidade a realização da leitura prévia das obras dos autores convidados para a Jornada e para a Jornadinha, com o intuito de preparar os leitores para o encontro e para a festa da literatura. Nesse processo, são realizadas leituras individuais, havendo, ainda, momentos para o compartilhamento das experiências vivenciadas, com vistas à formação continuada de leitores e de mediadores de leitura. 
A presente pesquisa, vinculada ao Programa de Pós-Graduação em Letras, na linha de pesquisa de Leitura e Formação do Leitor, tem como tema a gamificação como ferramenta para a formação de leitores, abordando mais detalhadamente as atividades propostas por meio do aplicativo JornadApp na $8^{\mathrm{a}}$ Pré-Jornadinha Nacional de Literatura.

As Jornadas Literárias dialogam com o contexto que exigem inovações e interatividade. A movimentação cultural permitiu troca de informações sobre o texto literário e promoveu o debate sobre livros e literatura, aproximando leitores e escritores. A principal inovação das Jornadas Literárias de 2017 foi a difusão, democratização das ações pela cidade, fazendo com que Passo Fundo vivenciasse a leitura e a literatura, tornando-se, efetivamente a Capital Nacional da Literatura. No momento em que a Jornada descentralizou suas ações e se espalhou pelas ruas e por outros espaços, temos o conceito de leitura ampliado, o que oportuniza uma leitura de mundo da própria cidade.

\section{As Jornadas Literárias e as tecnologias digitais}

As Jornadas Literárias desde sempre foram marcadas pelo contato prévio com as obras de autores presentes no grande evento. A pré-Jornadinha então se constitui na leitura de uma ou mais obras dos autores que participarão da
Jornadinha Nacional de Literatura. É o momento em que os alunos, mediados pelos professores, são incentivados a conhecer os escritores e suas respectivas obras, bem como desenvolver discussões. Os professores, juntamente com os alunos escolheram os livros que seriam trabalhados, dentre aqueles indicados e cujos autores estiveram presentes na Jornadinha Nacional de Literatura e, após todo o trabalho com o livro, os alunos compartilham suas experiências vivenciadas por meio da arte, seja um teatro, música, pintura, gravuras, construindo e formando jovens leitores.

Uma das primeiras ações da $16^{\text {a }}$ Pré-Jornada e da $8^{\text {a }}$ Pré-Jornadinha aconteceu ainda em maio de 2017. Cerca de 370 professores participaram do curso "Leitura multiplicada: a formação do agente de leitura"1, promovido pela comissão organizadora da $16^{\text {a }}$ Jornada e da $8^{\text {a }}$ Jornadinha Nacional de Literatura. O curso gratuito teve atividades ao longo dos meses que antecederam à Jornada.

Os encontros que aconteceram de forma presencial e virtual, contaram com a difusão e aplicação de materiais produzidos pela organização das Jornadas de Literatura, como a demonstração das práticas leitoras e das propostas de multiplicação de leitura. Além disso, foi apresentado um resumo de uma das principais novidades da Pré-Jornada e Pré-Jornadinha, o JornadApp, aplicativo oficial da Jornada, em que os agentes de leitura tiveram um papel fundamental. 
Entre os objetivos do projeto estava o de envolver alunos e professores nas Jornadas Literárias, cujo papel é incentivar a leitura, o encontro de leitores, escritores, artistas, pesquisadores, professores, educadores, alunos, intelectuais e comunidade leitora.

Os agentes de leitura atuaram como mediadores do conhecimento, em cada escola, auxiliando no desenvolvimento das atividades propostas no material de apoio que foi constituído de atividades em meio digital - como o Caderno de Atividades ${ }^{2}$ on-line e as atividades propostas no JornadApp na Escola, elaboradas para aplicação em salas de aula, na conexão via computadores e mobiles, e apresentadas à comunidade em geral nas Estações de Leitura.

Durante a Pré-Jornada e a Pré-Jornadinha, entre os meses de julho e setembro, além de ler as obras, estudantes, professores e a comunidade em geral puderam interagir com os livros por meio do JornadApp, aplicativo oficial da Jornada, que tem como base as obras dos escritores convidados para aquela edição. O JornadApp integrou as atividades da Pré-Jornada e da Pré-Jornadinha, que envolvem o período de leitura das obras dos autores que participaram da festa literária, realizada em outubro. É um aplicativo interativo disponível gratuitamente em sistema Android e iOS. $\mathrm{O}$ sistema possui duas funcionalidades e atinge públicos diferentes. Uma delas é o "Projeto Transversais: rotas leitoras", que integra a Pré-Jornada e permite que qualquer pessoa caminhe pela cidade, caçando livros por locais históricos e pontos turísticos da cidade.

A outra funcionalidade do aplicativo é o "JornadApp na Escola" destinado aos alunos de ensino fundamental ( $1^{\circ}$ ao $9^{\circ}$ ano) e integra a Pré-Jornadinha. Nessa função do aplicativo ${ }^{3}$, há atividades destinadas a estudantes em conformidade com os anos escolares dos grupos inscritos. Para que uma equipe possa participar, é necessário um dispositivo por grupo, de forma que a equipe possa cumprir as tarefas em sistema de gamificação da leitura.

A ideia do jogo não era uma competição entre escolas, mas entre as turmas da própria instituição. Não havia limite de participação de turmas por escola e as atividades tinham diferentes dificuldades e pontuações. Depois de realizadas as atividades via aplicativo, as escolas foram separadas por região e participaram das "Estações de Leitura" para socializar as atividades realizadas na Pré-Jornadinha, destacando o protagonismo dos jovens leitores, dos mediadores e das escolas por meio da criatividade.

\section{Jornadapp na escola: a} pré-jornadinha gamificada

O JornadApp acompanha as novas formas de difusão da literatura no meio digital. Rettenmaier (2017) observa que a "literatura, que por muitos anos ficou limi- 
tada ao universo real, físico, agora segue a tendência da vida, que está cada vez mais on-line". As tecnologias de informação e comunicação, como por exemplo, os smartphones, são os novos ambientes da escrita e, especialmente, da leitura, convergindo todas as mídias. As tecnologias móveis e ubíquas representam uma inovação nas práticas pedagógicas, ampliando os tempos e espaços de aprendizagem para além das salas de aula, aliando dinâmicas de colaboração e interatividade, caracte-

Figura 1 - Telas iniciais do aplicativo

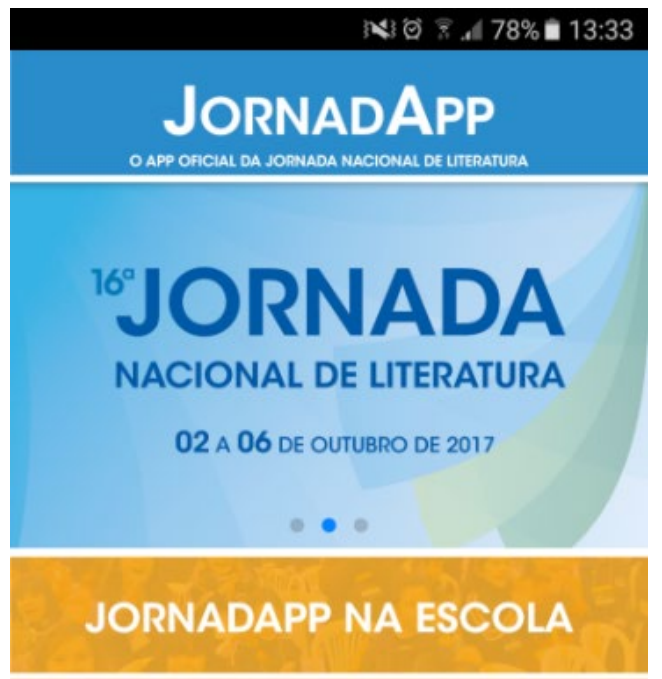

\section{PROJETO TRANSVERSAIS}
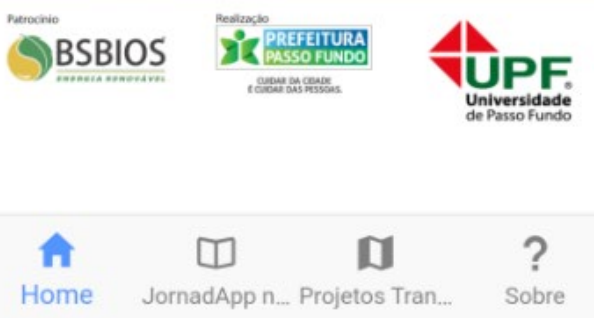

rísticas da cultura digital atual. O leitor deixa de ser um mero receptor e torna-se protagonista do conhecimento.

O mediador, então, fazia o download do aplicativo em seu celular, cadastrava a turma, ou a escola, e registrava as tarefas cumpridas. Assim, muitos professores e escolas da região de Passo Fundo que não participaram das "Estações de Leitura", puderam trabalhar as atividades com seus alunos, sem a contagem de pontos.

ㅂ.

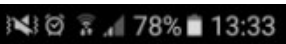

\section{$\mathrm{Na}$ Escola}

\section{LOGIN}

\section{NOVO PARTICIPANTE}

\section{VISITANTE}

Fonte: autor (2017). 
Como se observa nas imagens acima e já referido anteriormente, a tela inicial do aplicativo possuía duas funções: JornadApp na Escola e Projetos Transversais. $O$ mediador clicava na primeira opção, cadastrava-se como novo participante, caso fosse o primeiro contato com o aplicativo; ou fazia seu login normalmente ou clicava em visitante, caso não pertencesse a cidade de Passo Fundo ${ }^{4}$. Após, podia escolher com qual ano do Ensino Fundamental iria trabalhar, e uma lista de obras e atividades estava à disposição.

O aplicativo, então, contou com 21 obras dos escritores participantes da Jornadinha e com 22 atividades gamificadas que foram divididas por série/ano Do primeiro ao quinto ano do Ensino Fundamental I, o aplicativo disponibilizou 10 atividades pertencentes às obras $O$ livro que lê gente de Alexandre de Castro Neto, Monstros do cinema de Daniel Kondo e Augusto Massi, Poeminhas da terra de Márcia Leite, O livro do palavrão, de Selma Maria, Adélia de Jean Claude Alphen, Roupa de brincar de Eliandro Rocha, Tony Moon de Pedro Duarte, Oriê de Lúcia Hiratsuka, Como nasceram as estrelas de Clarice Lispector. Do sexto ao nono ano do Ensino Fundamental II, 12 atividades gamificadas foram disponibilizadas: A arma escarlate de Renata Ventura, Flor de Guernica de Pablo Morenno, Uma escuridão bonita de Ondjaki, Quem matou o livro policial de Luiz Antônio de Aguiar, Ouro, fogo e megabytes de Felipe Castilho, Auto da Compadecida de Ariano Suassuna, Iluminuras de Rosana Rios, Quando o Sol encontra a Lua de Renata Tufano, A fonte do esquecimento de Heloisa Prieto, O homem que fazia chover de Carlos Drummond de Andrade, $O$ navio das cores de Moacyr Scliar.

As atividades propostas no JornadApp na Escola foram desenvolvidas pela comissão organizadora da $8^{\underline{a}}$ Jornadinha Nacional de Literatura. Com a proposição de atividades gamificadas das obras dos autores indicados para o evento, na forma de desafios, o objetivo foi a interação entre autores, obras e leitores, a fim de despertar a criatividade dos alunos por meio da produção e da socialização dessas práticas. $\mathrm{O}$ aplicativo possibilitou diferentes desafios gamificados em que professores e alunos trabalhassem juntos, trocando experiências sobre os autores, sobre as obras, não levando apenas o efeito estético que ela proporciona, mas também, às reflexões sobre a humanidade, sobre as diferenças.

Embora essas práticas gamificadas, esses jogos, despertem a diversão e o entretenimento, para Santaella (2013, p. 251), o aspecto lúdico também é muito importante para o "incremento e desenvolvimento cognitivo". O jogo quando é divertido, motivador torna-se extremamente excitante, mesmo sendo um jogo para aprendizagem, tornando-se desafia- 
dor e promove o desenvolvimento mental e o conhecimento. De acordo com a autora (2013a, p. 254), "o lúdico, de que os jogos são a expressão mais legítima, é o lugar no qual as forças da razão e da sensibilidade se fazem presentes". É o elemento que fornece a potência para explorar e adquirir de novas aprendizagens.

O sucesso do JornadApp foi que, além de dar ênfase aos aspectos didáticos, levou em conta muito dos aspectos lúdicos. Uma das atividades gamificadas propostas foi com a obra O livro que lê gente, de Alexandre de Castro Gomes (2016). A obra narra a história de um livro velho, que ao invés de ser lido, aprende a ler as pessoas, invertendo os papéis. Depois de ser colocado longe do alcance dos leitores, no alto de uma estante, ele faz amizade com outro livro antigo que o ensina a enxergar a diversidade e a riqueza da vida humana ao observar as pessoas que frequentam uma biblioteca.

A atividade proposta foi destinada aos alunos do $1^{\circ}$ ao $5^{\circ}$ ano do Ensino Fundamental I. A ideia era que, após a leitura da obra, os alunos construíssem uma capa de livro com uma foto da turma e um título. Após a atividade, o mediador, via aplicativo, postava a foto e enviava à comissão organizadora da Jornadinha. As fotos mais criativas, que não saíssem tremidas e que cumprissem as regras da tarefa marcavam pontos. A comissão recebeu dezenas de fotos da atividade proposta. Os alunos puderam colaborar na construção da capa, sempre com a ajuda do mediador, despertando, assim, o senso crítico, a criatividade e o protagonismo.

Figura 2 - Atividades desenvolvidas pelos alunos com o livro $O$ livro que lê gente
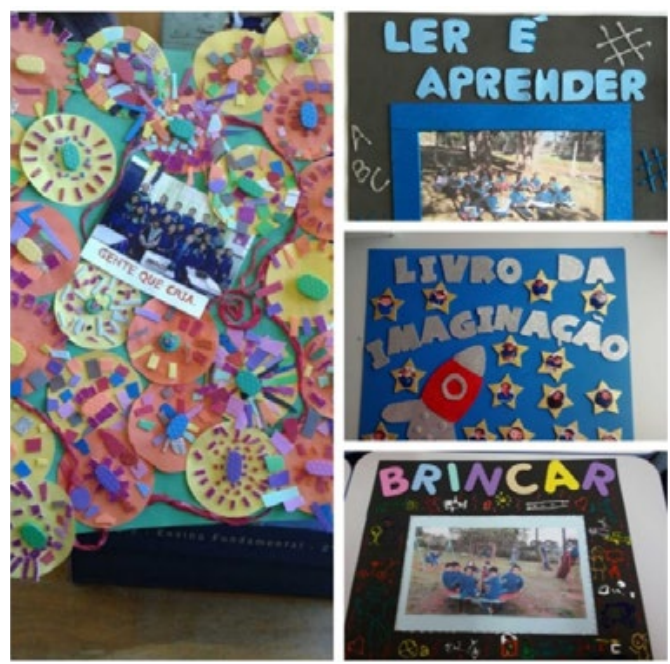

Fonte: acervo Jornada, 2017.

As atividades propostas pelo aplicativo abrangeram todas as formas de comunicação, desde a escrita coletiva até fotos. Foram propostas pinturas, criação de poema, confecção de jornal, produção de vídeos, descoberta de enigmas. Algumas atividades, as meritórias e classificatórias, foram respondidas no próprio aplicativo, como as do $O$ livro do palavrão, de Selma Maria; Poeminhas da Terra, de Márcia Leite; e Como nasceram as estrelas, de Clarice Lispector.

Por exemplo, na obra de Selma Maria, O livro do palavrã $o^{6}$ - destinado aos alunos do $1^{\circ}$ ao $3^{\circ}$ ano do ensino funda- 
mental I - mostra, de forma criativa, as diferenças entre o aumentativo e o diminutivo das palavras, seu significado e a forma correta de utilizá-las, dependendo do momento, brincando, assim, com a língua portuguesa. A proposta, então, sugerida pelo aplicativo, era que o professor, juntamente com os alunos construíssem duas palavras que, quando acrescidas da terminação -ão, mudassem completamente de sentido. Para comple- tar a atividade, a professora postava no aplicativo as palavras construídas pelos alunos. Alguns exemplos que a comissão da Jornada recebeu foram: pimenta (de ficar brava) e pimentão (de ficar vermelho, de comer); milho (de comer), milhão (de comer, de dinheiro). Nessa atividade, o lúdico esteve presente no desafio das crianças ao construir palavras, e perceber como o sentido muda quando flexionadas em grau.

Figura 3 - Proposta de atividade sobre a obra O livro do palavrão de Selma Maria

\section{3) จิ $484 \%$ 14:34}

\section{$\leftarrow$ VOLTAR O livro do palavrão}

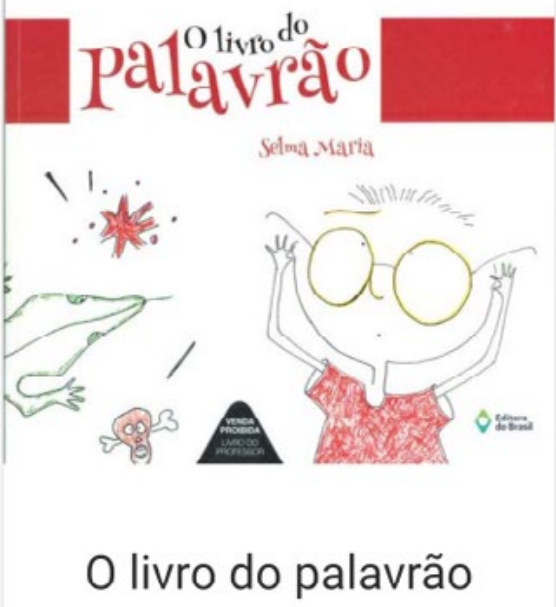

Selma Maria

Atividade:

Quem conhece o melhor palavrão?

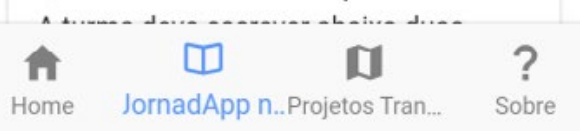

曰

$\leftarrow$ vOLTAR O livro do palavrão

A turma deve escrever abaixo duas palavras que modifiquem seu sentido quando ganham um grande "ão".

Por exemplo:

Anão, de Ana (linda menina) e anão (um cara pequeno).

Botão, de bota (aquilo com chulé) e botão (o que um dia cai da camisa). Balão, de bala (nunca de revólver, mas de açúcar) e balão (que sobe, sobe $e$ foge para o céu).
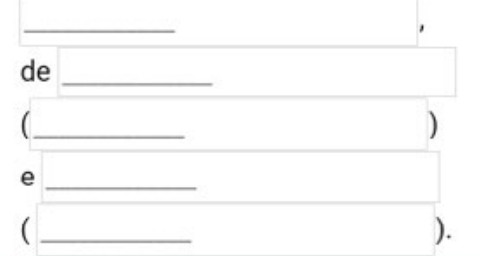

ENVIAR
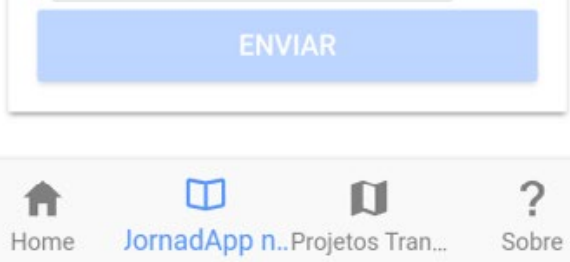

Fonte: arquivo pessoal, 2017. 
Das obras da Jornadinha, teve uma que se destacou por conta de duas atividades sugeridas pelo aplicativo. O livro Monstros do cinema ${ }^{7}$, de Augusto Massi e Daniel Kondo, conquistou o coração dos alunos e dos professores. As duas atividades propostas para os alunos do $4^{\circ}$ e $5^{\mathrm{o}}$ ano do Ensino Fundamental I despertaram a curiosidade e a criatividade dos alunos. Na primeira atividade, a ideia era que os alunos criassem um monstro, e a segunda atividade tinha como objetivo uma "invasão" dos alunos na hora do intervalo, num estilo flash$m o b$, vestidos de monstros e dançassem a música Thriller, de Michael Jackson.

O mediador foi o responsável pela gravação dessa tarefa e após, a postou no Youtube e enviou o link para a comissão julgadora, por meio do JornadApp, como monstra as imagens acima. A proposta, então, tinha como objetivo despertar a imaginação dos alunos. Ao som da música de Michael Jackson, eles se fantasiaram, fizeram coreografia e "invadiram" a hora do recreio, e de forma criativa, com máscaras, maquiagem assustadora, espalharam o medo pela escola, como podemos perceber no print abaixo do videoclipe recebido pela comissão organizadora do evento e publicada no YouTube, como podemos perceber pelos prints a seguir:
Figura 4 - Flashmob da música Thriller de Michael Jackson no Instituto Menino Deus - Passo Fundo

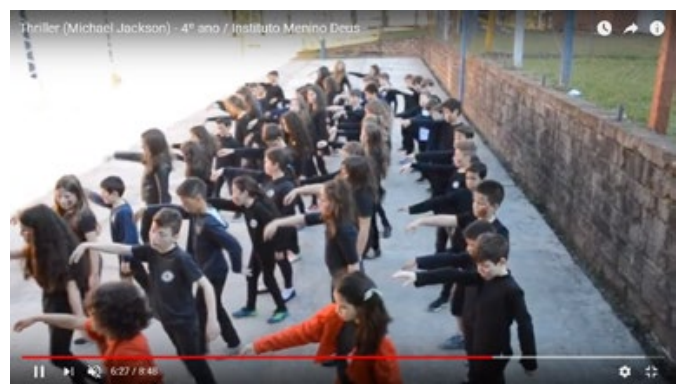

Fonte: YouTube ${ }^{8}, 2017$.

Outro livro e atividade que despertou o interesse dos alunos foi A Flor de Guernica, do escritor passo-fundense Pablo Morenno, destinada aos alunos do $8^{\circ}$ e $9^{\circ}$ ano do Ensino Fundamental II. Porém, o que se percebeu foi o engajamento de todas na escola, de todas as turmas para deixar os muros mais coloridos, com vida, com literatura. A obra serviu de inspiração para que os alunos criassem um painel no pátio da escola, ou usassem o quadro da sala de aula

A proposta era trabalhar o livro em sala de aula e, a partir dele, desafiar os alunos a criar um mural que tivesse relação com a obra. Ao contrário do livro, que traz temas como abandono, injustiça, perdas e dores, os alunos foram convidados a pintar a esperança. Além das flores, o mural também ganhou palavras que as crianças consideraram importantes, percebe-se nessa atividade a importância do significante fraturado de Iser (2002). 
Ao mesmo tempo que algo é denotado, nega-se tal uso, sem que seja abandonado aquilo que se designa na primeira instância. O significante funciona como um "análogo para a figuração de algo mais". "Algo ausente é presentificado: o significante fraturado "invoca alguma coisa que não é pré-dada”, mas engendrada por ele, que habilita o leitor a dotá-lo de uma forma tangível”. Não é mais o significado do texto que está em questão, mas a ativação do imaginário pelo leitor:

Figura 5 - Releitura produzida pelos alunos sobre a obra Flor de Guernica de Pablo Morenno

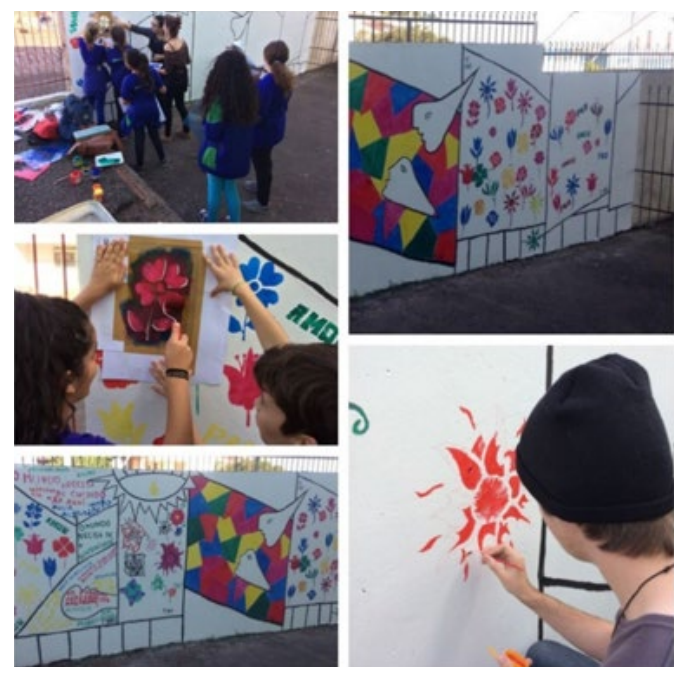

Fonte: acervo da Jornada, 2017.

Assim, não importa, propriamente, o assunto de que trata um texto, mas, sim, que esse cumpra a função de provocar o leitor para ocupar seu lugar na geração de imagens e na produção de sentidos.
É bom lembrar que, para serem utilizados com fins educacionais, as atividades gamificadas, ou os jogos propriamente ditos, precisam possuir objetivos de aprendizagem bem definidos, ensinar conteúdos, não só apenas da Língua Portuguesa e Literatura, mas das Artes, da Geografia, da História, da Matemática, da Sociologia, promovendo o desenvolvimento de competências e ampliando a capacidade intelectual e cognitiva dos mediandos. E para que isso aconteça, os objetos gamificados, como o JornadApp, precisam se estruturar nos seguintes fatores: objetivos e regras, contexto significativo de aprendizagem, feedback, colaboração entre os jogadores, competitividade, desafios, como se fosse um jogo, seja ele real ou virtual, seja ele apenas no texto, como fora dele.

Os games são, portanto, uma alternativa ativa e autônoma, se comparados às metodologias tradicionais usadas em contextos de ensino e aprendizagem. A mudança principal é a troca de um processo tradicional de ensino para um que alie diversão e aprendizagem, facilitando uma aprendizagem por descobertas (SANTAELLA, 2013, p. 258).

De acordo com Gee (2003), os games estão estruturados de modo a encorajarem a aprendizagem não passiva, incentivando o jogador a compreender e a estabelecer inter-relações entre signos, estimulando a reflexão, a apropriação de significados, o autoconhecimento e o desenvolvimento de competências. Esse processo caracteriza-se pelo ambiente co- 
laborativo, que ocorreu nas turmas, nas escolas, nas comunidades e pelo estabelecimento de relações entre comunidades de jogadores. Isso só é possível porque uma das características primordiais dos jogos é a coautoria.

Essa coautoria é fundamental no JornadApp, pois os estudantes, juntamente com seus professores, tornaram-se colaboradores, criadores, coautores do próprio conhecimento, por meio da magia da literatura. Talvez o que faltou para o aplicativo foi uma interface onde a interação fizesse parte, oferecendo para os alunos e professores um ambiente em que esses usuários queiram estar, "explorar, ficar entretidos em tal intensidade que aprendam sem sentir que estão aprendendo (SANTAELLA, 2013, p. 262)", aliando desafios, fantasia e curiosidade.

Ser coautor foi muito importante para o desenvolvimento literário nesses leitores. Petit (2009, p. 22) acredita que a leitura é marcada pela "liberdade do leitor”. Os leitores, então, apropriam-se dos textos, dão outros significados, mudam seu sentido, interpretando do seu modo, introduzindo "seus desejos entre as linhas (p. 26)". Os leitores, a partir do aplicativo, jogaram com o texto, com as obras por meio das reescritas, transformando-as e os transformando também.

Basicamente é o que ocorreu com a atividade gamificada para a obra Quem matou o livro policial? de Luiz Antônio Aguiar. O livro, que é um divertido thriller sobre detetives, assassinatos e sobre como escrever um romance policial, e tem como palco a Capital Nacional da Literatura, busca desconstruir a imagem que se tem de detetives. No início da proposta, destinada a alunos de $7^{\circ}$ e $8^{\circ}$ ano, se faz uma intertextualidade com a música Detetive da banda gaúcha Comunidade Nin-Jitsu. A tarefa era a construção de dez ensinamentos de um detetive atrapalhado, porém, usando o QRCode ${ }^{9}$ para descobri-los.

Figura 6 - QRCode criado pelos alunos do $8^{\circ}$ ano da Escola Municipal de Ensino Fundamental Roberto Textor - Jacuizinho/RS

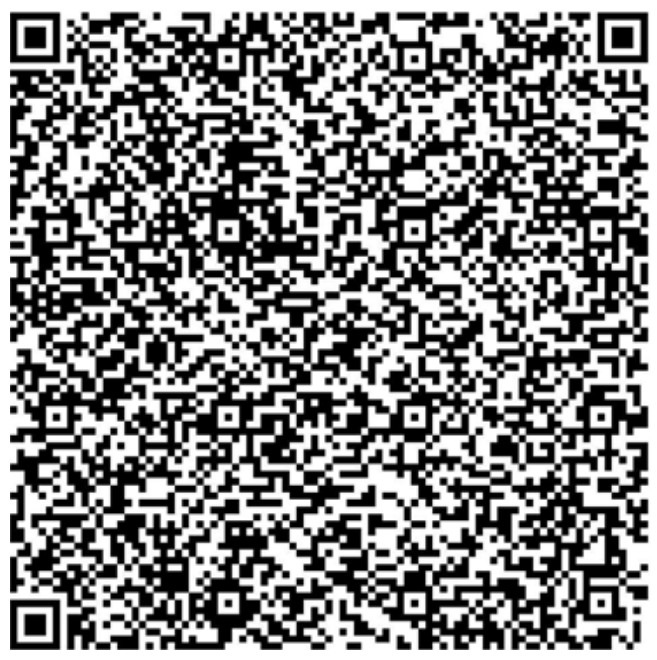

Fonte: Acervo Jornada. 
Figura 7 - Dez ensinamentos elaborados pelos alunos do $8^{\circ}$ ano da Escola Municipal de Ensino Fundamental Roberto Textor - Jacuizinho/RS

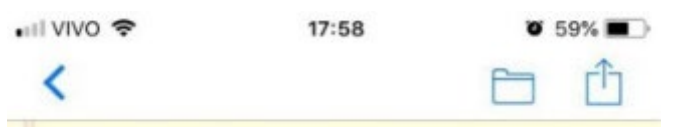

$1^{\circ}$ Utilização de vários acessórios inusitados;

$2^{\circ}$ Curioso e nada discreto;

$3^{\circ}$ Métodos de interrogatório

questionáveis, pelas perguntas

aparentemente sem cabimento;

$4^{\circ} \mathrm{Faz}$ uso de entorpecentes para ambos

(detetive - investigado);

$5^{\circ}$ Seu meio de locomoção "Hoverboard"

acoplado a um jegue;

$6^{\circ}$ Uma agenda de anotações com GPS

acoplado o qual realiza operações ao

contrário;

$7^{\circ}$ Ter um assistente versátil (uma barata

com poderes de transformação);

$8^{\circ}$ Sofrer de sonambulismo (todas as

suas ações são realizadas sob esse

efeito);

$9^{\circ}$ Utilização do método hipnótico, porém,

o hipnotizado é o detetive;

$10^{\circ}$ Por onde passa deixa sempre um

vestígio (pato de borracha).

Seja Original - Abra Sua Conta GRATIS - 425.269 pessoas usam isso.

Fonte: Acervo Jornada, 2017.

Percebe-se nessa proposta a importância da "cultura gamer" no cotidiano dos alunos, unindo o entretenimento e a educação, e que é por muitos professores ignorada. Para Santaella (2013, p. 219),

[...] o game como produto cultural, é visto, sob diversas perspectivas, enquanto mídia, manifestação de arte, nova forma de aprendizagem e até como o mais recente ícone da cultura pop.
Porém, para grande parte dos educadores a tecnologia é algo externo, algo que não faz parte do mundo escolar, algo que não deve ser trazido para dentro da escola, por receio ou por falta de preparo por parte desses que a criticam.

As atividades gamificadas propostas pelo aplicativo, como a analisada, levaram os estudantes a aprender sem perceber, desenvolvendo habilidades, principalmente para trabalhar em equipe. É por isso que se deve perceber a influência da tecnologia nas atividades humanas e saber aproveitá-la de modo eficiente, produtivo e com o objetivo de construir uma sociedade mais justa, e a escola tem papel fundamental nessa tarefa, pois

[...] ela é (ou deveria ser) um ambiente de aprendizagem destinado a preparar os indivíduos para o mundo, um ambiente onde são trabalhados diariamente os processos de ensino e aprendizagem desses indivíduos que nela se encontram (FARDO, 2013, p. 31).

A partir da análise do aplicativo e das atividades gamificadas, percebe-se que houve uma restrição, por conta dos professores, a utilização de tecnologias em sala de aula. Algumas atividades realizadas não foram pontuadas pois, alguns mediadores não entenderam as propostas sugeridas. Chega-se a essa conclusão também ao se analisar a adesão das atividades. Aquelas que eram mais simples de se trabalhar, que não precisavam das novas tecnologias - ce- 
lular, imagens, computador, redes sociais - foram mais desenvolvidas em sala de aula. E as que exigiam um comprometimento e um conhecimento maior, foram deixadas de lado. Acredita-se que que tal resultado se dê por falta de conhecimento dessas tecnologias, medo ou comodismo.

A educação necessita de abordagens que consigam incorporar melhor os fenômenos do mundo imerso na cultura digital, e a observação de um dos fenômenos trazidos pelas tecnologias digitais que parece mais cativar pessoas de todas as idades vem à tona: os games. Esse gênero de entretenimento tem muito a ensinar para a área da educação. Assim, lamenta-se que boa parte dos educadores adote a tecnologia apenas para uso pessoal, por meio das redes sociais como Facebook e WhatsApp e as deixem de fora de suas práticas pedagógicas. A tecnologia cria uma cultura, um novo modelo de sociedade, então, para o professor, a aplicação dessas tecnologias em suas aulas nas salas, implica conhecer as potencialidades desses recursos em relação ao ensino das diferentes disciplinas do currículo, bem como promover a aprendizagem de competências, procedimentos e atitudes por parte dos alunos, e utilizar todas as potencialidades que os games, que as atividades gamificadas possam oferecer.

E para que isso aconteça, os jogos, ou os objetos gamificados, como o JornadApp, precisam se estruturar nos seguintes fatores: objetivos e regras, contexto significativo de aprendizagem, feedback, colaboração entre os jogadores, competitividade, desafios. Os games são, uma alternativa autônoma e ativa, quando se compara com a metodologia tradicional usada em sala de aula. Os games aliam diversão à aprendizagem, facilitando-a por meio de descobertas, de enigmas, de criação, de aprendizagem, de autoria.

O JornadApp além de dar ênfase aos aspectos didáticos, levou em conta muito dos aspectos lúdicos, o que falta para muitos jogos educativos ou aplicativos gamificados usados na busca por conhecimento e aprendizagem. Houve então, uma inversão de papéis, por conta do aplicativo. O leitor sendo o protagonista, tornou-se o autor da releitura, da criação de uma nova obra. E o fato de colocá-los no centro das atenções, sendo protagonistas da movimentação literária, despertou ainda mais a paixão pela literatura e pelos livros. Os alunos chegavam a ler mais de uma obra por semana, a fim de trabalharem colaborativamente para que toda a comunidade pudesse ver e sentir seus trabalhos nas "Estações de Leitura". Eles cumpriram regras, tiveram metas, receberam feedback das atividades e foram premiados.

O leitor, assim, não é só um construtor de sentidos, mas alguém capaz de ampliar esses sentidos e colocar em prática sua própria experiência. Para Iser (1999, p. 48), o "leitor não mais pode 
ser instruído pela interpretação quanto ao sentido do texto. Mais instrutivo seria analisar o que sucede quando lemos um texto", pois é em virtude da leitura que os textos se tornam realidade,

[...] e isso vale também para aqueles cuja significação já se tornou tão histórica que não tem mais um efeito imediato, ou para aqueles que só nos tocam quando constituímos o sentido da leitura (ISER, 1999, p. 48)

Assim experimentamos um que pode ser que não exista, mas que seja possível compreender. E a compreensão se faz por meio da literatura, do jogo da literatura com o leitor.

As obras lidas, as atividades lúdicas realizadas com a gamificação, as releituras feitas, a apresentação das atividades, seja ela na escola ou nas "Estações de Leitura", transformaram e formaram novos leitores:

[...] é porque esse sujeito sensível, vulnerável e ex/posto é um sujeito aberto a sua própria transformação. Ou a transformação de suas palavras, de suas ideias, de seus sentimentos, de suas representações, etc. De fato, na experiência, o sujeito faz a experiência de algo, mas, sobretudo, faz a experiência de sua própria transformação. Daí que a experiência me forma e me transforma (LARROSA, 2011, p. 7).

\section{Considerações finais}

Com base no tema de pesquisa "a gamificação como ferramenta para a formação de leitores", abordando mais detalhadamente as atividades propostas pelo apli- cativo JornadApp na $8^{\text {a }}$ Pré-Jornadinha Nacional de Literatura, percebeu-se que a gamificação, ao mesmo tempo em que cresce como método ou estratégia aplicada em várias áreas de atuação humana, principalmente, na educação, ainda necessita de muita pesquisa, tanto teórica quanto empírica (talvez essa última seja mais necessária nesse momento).

No que tange à gamificação e ao aplicativo JornadApp na Escola, pode-se considerar inovador na área da gamificação e da leitura, um recurso com o objetivo de tornar a leitura e o trabalho com a literatura, um hábito prazeroso. Apesar de ser um software com atividades gamificadas com base no conteúdo das obras literárias sugeridas na Jornadinha, as atividades procuram mediar a leitura por meio de elementos presentes nos jogos, tão presente na vida cotidiana fora da escola, que é a função da gamificação: usar elementos presentes nos jogos, mais especificamente nos videogames, em ambientes de não-jogo.

Infere-se que o aplicativo, então, contribuiu com a democratização da leitura e da literatura, que é um dos objetivos principais da Jornada e da Jornadinha, pois ele atraiu e incentivou a leitura, contribuindo para sociedade mais crítica e reflexiva. Percebeu-se que os alunos aderiram às atividades gamificadas, compartilhando as experiências e sendo protagonistas na própria aquisição de conhecimento por meio da leitura. 
Porém, durante as análises, dois problemas foram levantados. O primeiro refere-se ao questionamento de que os professores têm conhecimento de como utilizar o aplicativo. Essa premissa parte de que muitos professores apenas usam seus celulares para aplicativos de redes sociais, e não têm o mesmo conhecimento tecnológico que seus alunos.

Outro desafio que se apresenta é o fato de que a maioria dos professores e educadores envolvidos com ambientes de aprendizagem atualmente parece não ter o hábito de interagir com games. Pelo contrário, muitos têm a visão de que eles são obstáculos à aprendizagem, são distrações que tiram os jovens do caminho da construção de seus conhecimentos.

Conclui-se, então, que a gamificação se apresenta como uma estratégia viável para o engajamento e motivação dos alunos no desenvolvimento de competências na aprendizagem de literatura, devendo ser difundida entre os docentes, a fim de se obter melhores resultados na formação de novos leitores.

\section{Gamification in the 8th Pré- Jornadinha Nacional de Literatura}

\section{Abstract}

This paper aims to analyze the contribution of gamification in the construction and formation of new readers through the application JornadApp na Escola, which was used as a re- source in the 8th Pré-Jornadinha Nacional de Literatura. The theoretical references of this research are based on the studies of Michele Petit, on the issue of reader formation; in the studies of James Paul Gee, Jane McGonigal with regard to games and gamification; and about playful learning and gamification in education, the contributions of Lucia Santaella. The research, descriptive and qualitative, observed, recorded and analyzed the data in the light of the theoretical assumptions listed, without the interference of the researcher and sought to present the relevance of literary literacy through gamified practices concluding that gamification is presented as a viable strategy for engaging and motivating students in the development of literature learning competences, and should be disseminated among the teaching community in order to obtain better results regarding the education of readers.

Keywords: Literature; Gamification; Jornadinha Nacional de Literatura; JornadApp na Escola.

\section{Notas}

1 O curso, com certificação de 40 horas, e envolveu profissionais da educação da rede pública e privada de Passo Fundo e região, que foram os responsáveis pela mobilização e pelo planejamento da leitura das obras em cada escola durante as ações da Pré-Jornada e da Pré-Jornadinha, tornando-os multiplicadores da leitura. Para Rettenmaier (2017), os professores tornaram-se "embaixadores da Jornada", sendo responsáveis pela formação de leitores e possuíram um papel fundamental e de grande responsabilidade nesse processo.

2 Disponível em: http://www.upf.br/_uploads/Conteudo/jornada/caderno_atividades_ VII_2017_final.pdf.

3 A plataforma esteve aberta para o cumprimento das tarefas, as quais deveriam ser desenvol- 
vidas por turmas, mediante a liderança de um professor (líder de equipe). O objetivo do aplicativo era auxiliar o professor quanto a realização das leituras das obras propostas para as diferentes etapas de ensino. O professor, ao apresentar-se e ao registrar a turma, era encaminhado às atividades em cada obra, e as tarefas estavam associadas aos livros da Jornadinha. Cada atividade era representada pela capa da obra.

4 As escolas públicas e privadas de Passo Fundo participaram das "Estações de Leitura" e também da gincana promovida pela Jornada. A escola que mais fizesse pontos por meio das propostas gamificadas se tornaria campeã. Já as escolas da região, tiveram suas Estações, porém, não foram contempladas na gincana.

5 As imagens das atividades enviadas via aplicativo pertencem ao acervo das Jornadas e foram cedidas para a pesquisa.

6 Na história, Joãozinho causa confusões quando decide usar apenas palavras no aumentativo, como, por exemplo, quando passou a chamar sua irmã Ana de Anão.

7 O livro traz onze monstros do cinema, em que podem ser montados e reconstruídos de acordo com a imaginação de cada leitor. Na parte final do livro há um levantamento histórico desses personagens, os filmes em que apareceram e a evolução que eles sofreram com o passar do tempo.

8 Flashmob filmado e disponibilizado no YouTube através do link: <https://www.youtube.com/

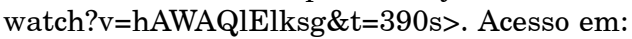
13 abr. 2018.

9 É um código de barras em 2D que pode ser escaneado pela maioria dos aparelhos celulares que têm câmera fotográfica. Esse código, após a decodificação, passa a ser um trecho de texto, um link e/ou um link que irá redirecionar o acesso ao conteúdo publicado em algum site (TECHTUDO, 2011). Disponível em: <http:// www.techtudo.com.br/dicas-e-tutoriais/noticia/2011/03/um-pequeno-guia-sobre-o-qr-code-uso-e-funcionamento.html>. Acesso em: 14 abr. 2018.

\section{Referências}

FARDO, Marcelo Luis. A gamificação como estratégia pedagógica: estudo de elementos dos games aplicados em processos de ensino e aprendizagem. 2013. 104 f. Dissertação (Mestrado) - Programa de Pós-Graduação em Educação, Universidade de Caxias do Sul. 2013. Disponível em: <https://repositorio.ucs.br/xmlui/handle/11338/457>. Acesso em: 5 jul. 2017.

GEE, James Paul. What Video Games Have to Teach Us About Learning and Literacy. 2. ed. Londres: St. Martin's Press, 2003.

ISER, Wolfgang. $O$ ato da leitura - v. 1. São Paulo: Editora 34, 1999.

ISER, Wolfgang. O jogo do texto. In: LIMA, Luiz Costa (org.). A literatura e o leitor: textos de Estética da Recepção. 2. ed. Tradução Luiz Costa Lima. Rio de Janeiro: Paz e Terra, 2002. p. 105-118.

LARROSA, Jorge. Experiência e alteridade em educação. Revista Reflexão e Ação, Santa Cruz do Sul, v. 19, n. 2, p. 4-27, jul./dez. 2011. Disponível em: <https://online.unisc.br/seer/ index.php/reflex/article/view/2444>. Acesso em: 4 nov. 2017.

MCGONIGAL, Jane. A realidade em jogo. Tradução Eduardo Rieche. Rio de Janeiro: BestSeller, 2012.

PETIT, Michèle. Os jovens e a leitura: uma nova perspectiva. Tradução de Celina Olga de Souza. 2. ed. São Paulo: Editora 34, 2009.

PETIT, Michèle. Leituras: do espaço íntimo ao espaço público. Tradução de Celina Olga de Souza. São Paulo: Editora 34, 2013.

RETTENMAIER, Miguel. In.: Revista Universo UPF. Festa da literatura envolve a comunidade. Passo Fundo: Universidade de Passo Fundo, n. 17, maio/jun. 2017.

SANTAELLA, Lucia. Comunicação ubíqua. São Paulo: Paulus, 2013. 